\title{
The Personal Data Protection Mechanism in the European Union
}

Submitted 11/05/20, $1^{\text {st }}$ revision 20/06/20, $2^{\text {nd }}$ revision 13/07/19, accepted $30 / 07 / 20$

\section{Tetiana L. Syroid ${ }^{1}$, Tetiana Ye. Kaganovska ${ }^{2}$, Valentyna M. Shamraieva ${ }^{3}$, Olexander S. Perederii ${ }^{4}$, Ievgen B. Titov ${ }^{5}$, Larysa D. Varunts ${ }^{6}$}

\begin{abstract}
:
Purpose: The article intends to assess the legal provisions of the current mechanism of personal data protection in the EU.

Design/Methodology/Approach: The authors studied the mechanism of personal data protection under the General Data Protection Regulation (EU) 2016/679 (GDPR) based on the concept of contextual integrity and analysis of EU legislation.

Findings: The adoption of the General Data Protection Regulation (EU) 2016/679 transformed approaches and concepts to the implementation of the personal data protection mechanism in the European Union. The article notes that the personal data privacy and protection is increasing, there is an ongoing unification of the legal status of personal data protection and the formation of a digital market for dissemination, exchange, control, and supervision of data.

Practical Implications: The authors proved that the GDPR has changed approach to personal data protection, the emphasis is now shifting to the formation of a digital market where the EU's role in ensuring regulation is crucial.

Originality/Value: The article identifies the emergence of a new protectionist legal system and strengthening of legal provisions regarding privacy.
\end{abstract}

Keywords: Personal data, personal data protection, GDPR, data protection authorities in $E U, G D P R$ implementation in EU.

JEL Codes: K24, L86.

Article Type: Research paper.

${ }^{l}$ Professor, V. N. Karazin Kharkiv National University, Kharkiv, 61000, Ukraine,

E-mail: syroid02@gmail.com

${ }^{2}$ Professor, V. N. Karazin Kharkiv National University, Kharkiv, 61000, Ukraine,

E-mail: t.e.kaganovskaya@gmail.com

${ }^{3}$ Associate Professor, V. N. Karazin Kharkiv National University, Kharkiv, 61000, Ukraine,

E-mail:76shamraeva@gmail.com

${ }^{4}$ Associate Professor, V. N. Karazin Kharkiv National University, Kharkiv, 61000, Ukraine,

E-mail: rexi2400@ukr.net

${ }^{5}$ Associate Professor, V. N. Karazin Kharkiv National University, Kharkiv, 61000, Ukraine

${ }^{6}$ Associate Professor, Kharkiv National University of Internal Affairs, Kharkiv, 61080,

Ukraine, E-mail: VLarisa@i.ua 


\section{Introduction}

The fundamental right to the personal data protection is enshrined in the Charter of Fundamental Rights of the European Union (Article 8) and in the Treaties (Article 16 of the Treaty on the Functioning of the European Union, TFEU) (European Commission, 2016; 2020). Improved methods of data mining, increasing volume of publicly available data have expanded the scope of the EU Data Protection Directive (Van Loenen, Kulk and Ploeger, 2016). "Data have become part and parcel of contemporary capitalism" (Laurer and Seidl, 2020). At the same time, the legislation on personal data protection remains underdeveloped, which requires a revision of the concept of personal data protection (Van Loenen, Kulk and Ploeger, 2016). Individuals should acquire the right to use their own personal data, which will ensure a more active role in personal data management and sustainable development.

The data strategy calls for the formation of a personal data market, a "single European data space" (European Commission, 2020), which necessitates the development of a mechanism and a clear structure for secure data exchange and increased accessibility. The importance of the research sector's access to data, which requires the functioning of the European Cloud Federation to monitor the personal data market, is increasing (European Commission, 2020).

In fact, personal data is transferred from the object of protection to the object of management, control and sale for the necessary purposes and in required volumes. The data market is emerging in the EU, its control and supervision is based on the EU legislation and initiatives.

The Regulation (EU) 2016/679 (General Data Protection Regulation), the EU's new data privacy law, aims to strike a balance between personal data protection rights and data processing needs of business and the research sector (Bentzen and Høstmælingen, 2019). As a result, a new concept of personal data protection based on a human-centered approach is being formed in the EU. This raises the issue of the effectiveness of the personal data protection mechanism in the EU. Given that the studies mostly cover the mechanisms of action of the EU Data Protection Directive (DPD) (Guinchard, 2018; Ilina, Miloradov and Kovaltchuk, 2019; Lewinski, Trzaskowski and Luzak, 2016), it is important to identify the features of the new innovative mechanism for personal data protection management in the EU.

The article is intended to assess the legal provisions of the current personal data protection mechanism in the EU. This article answers the following questions:

1. How flexible is the EU's personal data protection mechanism?

2. What are the differences within the EU regarding the implementation of the personal data protection mechanism in the EU?

3. What concepts does the EU data protection mechanism correspond to? 


\section{Literature Review}

Personal data is any information relating to a particular individual (personal data subject), including his last name, first name, patronymic, year, month, date and place of birth, address, family, social, property status, education, profession, income, other information. Legal remedies for personal data protection include administrative and judicial tools to restore the violated right to personal data protection (African Commission on Human and Peoples' Rights, 2013; 2016; 2019). Administrative means are used in case the entity decides to file a complaint to the supervisory authorities. Judicial remedies are used in case of opposition to the bodies of supervision and control on the basis of individual rights (Ungureanu, 2018). The latest innovative mechanism for personal data protection is the GDPR, which aims to facilitate administrative protection procedures and reduce the use of judicial data protection procedures.

Under the new regulation, personal data can be considered to be any personal information that may identify individuals, such as audio, address, video, texts, but also online identifies, such as IP addresses. The new EU law also introduces and discusses the idea of pseudonymous data, which is data attempting to identify the subject. The law also covers profiling. So, if genuine efforts have been made to pseudonymize personal data, the law looks favourably at these efforts in legal cases. Effectively, GDPR will apply to all types of data collected, whether it is directly identifiable or quantitative and technical data from or about any EU resident (Teatini and Matinmikko-Blue, 2020).

In Europe, the current law that covers personal data protection was approved by Parliament in April 2016 and after a two-year grace period, allowing national governments and regulators to get ready, was finally put into practice on 25 May 2018. The General Data Protection Regulation (GDPR) was enacted in order to enable EU citizens and institutions to get better control of their personal data (Teatini and Matinmikko-Blue, 2020). GDPR is the latest legal instrument for personal data protection, which will ensure the introduction of a new generation of communication infrastructure in many urban areas of Europe, Northeast Asia, North America and other regions of the world through an innovative mechanism for managing personal data protection(Teatini and Matinmikko-Blue, 2020). One of the focus of the law is to ensure transparency and accountability in order to minimize risks of individuals' data from being misused.

"The new GDPR provides a common framework more consistent with technological advances and globalisation, providing legal security to the personal data processing" (Martínez-Martínez, 2018). GDPR applies in cases where the data may be processed outside the EU, but the law of a Member State will be applied to that jurisdiction through the use of an instrument of public international law. The "territorial" provisions of the GDPR are the "long arm" of the law, ensuring that the GDPR applies beyond the EU. Under the GDPR, data processing is any set of operations 
with personal data or their processing, regardless of the processing methods (manual or automated) (Sharma, 2020a).

The GDPR sets out complex and stringent requirements for organizations or individuals doing business in the European Union (EU) and the European Economic Space, while dealing with the export of personal data outside the country (Sharma, 2020a). The GDPR allows for fines of up to $5 \%$ of income for breaches of privacy and data protection.

\section{Materials and Methods}

This article uses contextual integrity due to changes in the mechanism of personal data protection in accordance with the General Data Protection Regulation (EU) 2016/679 (European Commission, 2016). Contextual integrity, developed by Helen Nissenbaum, was the basis of the analysis, which provides a study of EU legislation on personal data protection.

The study is based on the review of scientific publications for 2016-2020, as a new personal data protection mechanism in the EU has been implemented since the adoption of the General Data Protection Regulation (EU) 2016/679. For analysis, the study used a search in Tandfonline and Wiley Online Library databases, which contains research on the features of the implementation of the mechanism of personal data protection, advantages and disadvantages. The following keywords were used to search for scientific publications: GDPR in EU, Data protection GDPR in EU, Data protection authorities in EU, GDPR implementation in EU, Data protection in EU, Personal Data protection in EU, Protection of personal data in the EU.

The search for studies allowed identifying journals that have a high Impact Factor (Table 1) according to 2019 Journal Citation Reports. The journals belong to the categories of Communication, Political Science, Law. During the period of 20162020, 19 studies were published on the implementation of the mechanism of personal data protection in connection with the adoption of the GDPR.

Table 1. Description of research sources

\begin{tabular}{|l|l|c|c|c|}
\hline \multirow{2}{*}{ Journal } & \multirow{2}{*}{$\begin{array}{l}\text { Impact } \\
\text { factor }\end{array}$} & \multicolumn{4}{|l|}{ ISI Journal Citation Reports, 2019 } & Communication & Political Science & Law \\
\hline Policy \& Internet (P\&I) & 2.763 & $16 / 92$ & $27 / 180$ & - \\
\hline European Law Journal & 1.589 & - & - & $43 / 154$ \\
\hline $\begin{array}{l}\text { Government Information } \\
\text { Quarterly }\end{array}$ & 6,430 & - & - & - \\
\hline $\begin{array}{l}\text { Journal of data protection \& } \\
\text { privacy }\end{array}$ & 4.162 & - & - & - \\
\hline Biometric Security and Privacy & 2.092 & - & - & - \\
\hline
\end{tabular}

Source: Developed by the authors. 
The main criteria for selecting publications were the subjects of research: the mechanism of personal data protection, tools for personal data protection, the implementation of the mechanism of personal data protection, the state of implementation of legislation on personal data protection.

We made a search by keywords using filters in Wiley Online Library databases: the period of 2016-2020, keywords or key phrases, journal. The search results repeated, i.e. contained the same studies by different keywords (Figure 1-2). The search results were an intermediate step. Qualitative analysis was conducted to select publications that corresponded to the main objective of the study - assessing the current mechanism of personal data protection in the EU. As a result, publications were selected, which partially or fully reveal the results of the study of the legal provisions of implementation of the personal data protection mechanism in the EU.

Figure 1. Search results for publications by keywords "Data protection in EU" wiley Online Library

239,629 results for "Data protection in EU" anywhere

* save search

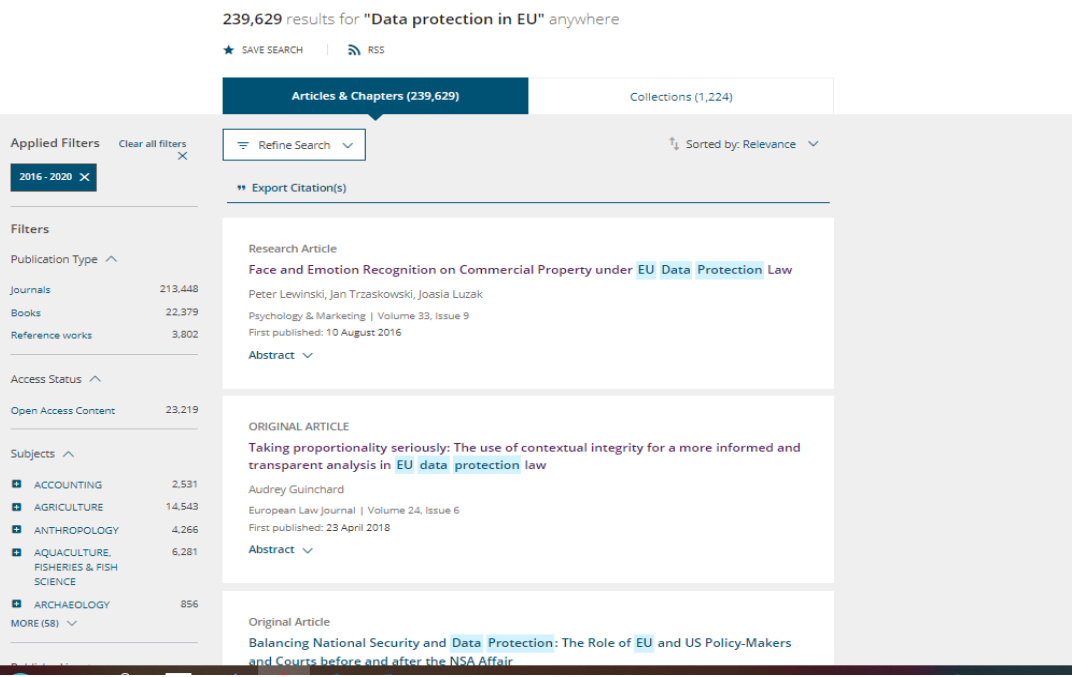

Source: Developed by the authors.

\section{Results}

The GDPR's entry into force provided a legal basis for the implementation of a culture of personal data privacy and protection in companies in accordance with EU standards for the first time (African Commission on Human and Peoples' Rights, 2013). The legal status of personal data protection is being unified, and a digital market for dissemination, exchange, control, supervision is being formed. "The development of the digital market deepened an imbalance in the relationship(s) between traders and consumers, leading to new questions as to the ethical boundaries of marketing and retailing" (Lewinski, Trzaskowski and Luzak, 2016). 
Figure 2. Search results for publications by keywords "GDPR"

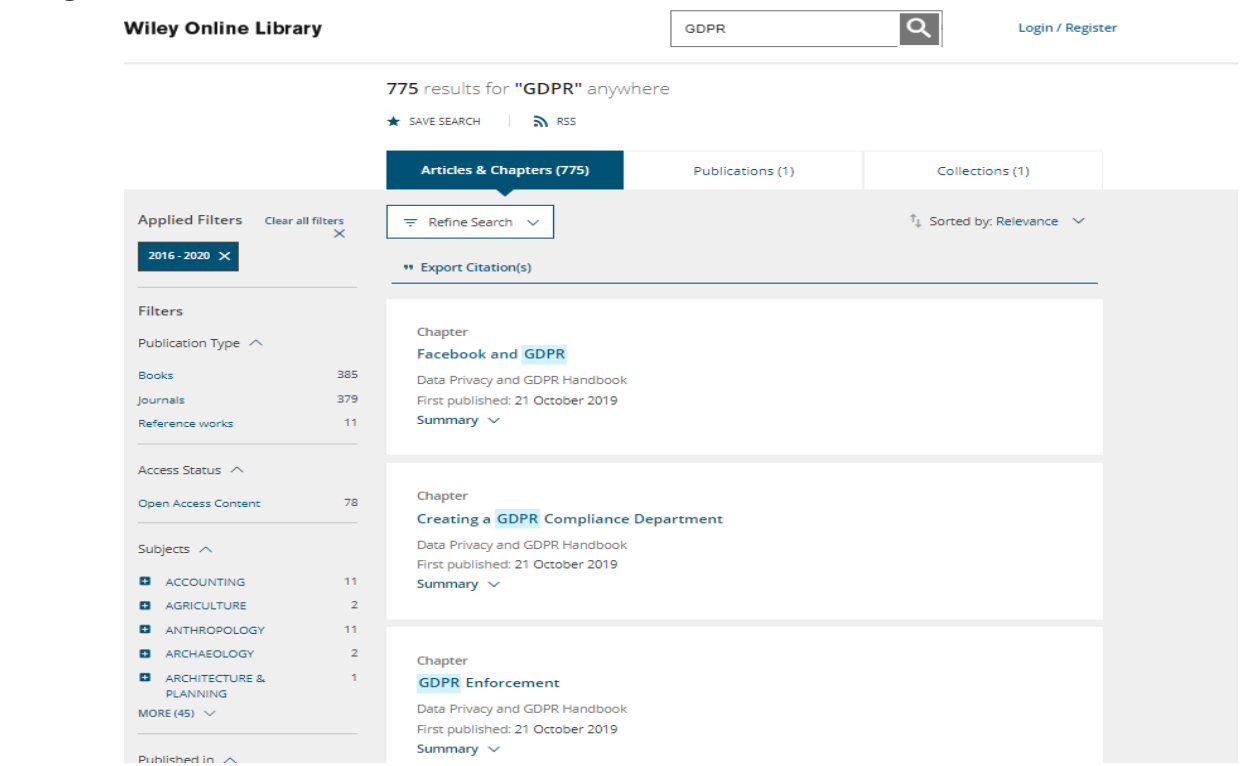

Source: Developed by the authors.

In June 2020, the European Commission published a report on the evaluation of the GDPR, which in particular assesses the GDPR's effectiveness in terms of functioning of the rules for the transfer of personal data to third countries and international organizations.

On May 5, 2017, the Federal Council of Germany approved the Gesetz zur Anpassung des Datenschutzrechts an die Verordnung (EU) 2016/679 and zur Umsetzung der Richtlinie (EU) 2016/680 o BundesdatenschutzgesetzBDSG (Federal Data Protection Act). This is the first national standard adapted to the GDPR's provisions. At the same time, in Spain, the new draft Law on Data Protection, presented in the report of the Council of Ministers on July 7, 2017, contained 78 articles on the adaptation and development of the GDPR.

The GDPR has changed approaches to personal data protection: from now on, the emphasis shifts from corporate sector data protection to personal data protection, the creation of a digital market, where the EU's role in ensuring regulation is crucial (Martínez-Martínez, 2018). Personal data became a new factor of production, "a new currency of change" (Martínez-Martínez, 2018), a new protectionist legal system to strengthen the law on privacy. This legal system needs unification and harmonization in accordance with national legislation, is territorially fragmented and differentiated within the EU. The GDPR ensured the formation of a protection mechanism based on a culture of prevention and compliance with regulatory requirements in order to ensure privacy. The GDPR is the basis for the formation of personal data protection management systems, and national agencies will be 
responsible for the effectiveness of the protection mechanism (Martínez-Martínez, 2018).

The GDPR provides for the implementation of two new personal data protection mechanisms: the mechanism of cooperation and the mechanism of consistency and logic (European Commission, 2020). GDPR and the functioning of cooperation mechanisms created an innovative management system based on independent bodies of personal data protection, their cooperation at the international level. National authorities have the right to use their powers for prevention purposes, imposing penalties, imposing time limits on the use and processing of data. The severity of the violations determines the size of the fines: from several thousand euros to millions. There is a possibility of a ban on data processing.

The new personal data protection mechanism cannot be assessed at the current initial stage of implementation in the EU. The protection authorities have, however, established cooperation based on a "single-window" mechanism and the use of mutual assistance, in particular in cross-border cooperation. "Data protection authorities developed their cooperation through the one-stop-shop mechanism and through a large use of mutual assistance. The one-stop-shop mechanism, which is a key asset of the internal market, is used to decide many cross-border cases" (European Commission, 2020). EU data protection authorities need human, financial and technical resources to make the mechanisms work more effectively.

The situation with the development of personal data protection mechanisms is uneven, in particular due to the reason for the operation of large multinational companies in certain countries (Ireland, Luxembourg). Personal data protection authorities are the most influential, they need much more resources for the effectiveness of data protection mechanisms. In Ireland, the Netherlands, Finland, and Luxembourg, the number of employees in the field of personal data protection increased in 2016-2019 (European Commission, 2020).

At the time of report generation (European Commission, 2020), all EU Member States, except Slovenia, have implemented GDPR into national law. The GDPR provides a sequence of formation of the personal data protection mechanism. This determines the fragmentary nature of the implementation of legal provisions.

The personal data protection mechanism needs to be improved in the context of facilitating people's access to personal data, making collective decisions and reducing costs of cross-checks and customs operations. The potential for the development of the mechanism is in the personal data transfer. Thus, a person will be at the center of the digital market, will be able to choose a service provider, combining different services, choose innovative services. This will indirectly affect competition between service providers. The mobility of personal data (for example, through the technology of data transfer on printed media in real time in a virtual 
environment) will simplify the mechanism of data transfer. Mobility of personal data is especially relevant in the field of medicine and research.

The GDPR and the Regulation on the Free Flow of Personal Data (European Commission, 2020) provide companies with opportunities, through competition and innovation, to ensure the free flow of data within the EU and to create a level playing field for companies established outside the EU. Personal data protection authorities provided small and medium-sized enterprises with templates for processing contracts, processing records, and hotlines for consultations in the field of data protection. Codes of conduct, certification mechanisms and standard contractual terms are tools to support small and medium-sized businesses in implementing a new personal data protection mechanism.

\section{Discussion}

The GDPR is becoming the global standard for how privacy and privacy protection laws should be shaped. In essence, it sets the rules which guide companies in personal data processing. Legislators cherished the idea of consent, which means companies often have to ask users for permission to use their data. The law also stipulates that third party data sharing will be more restricted since they will have to offer a reasonable explanation for why and how long they need the data and EU residents now have the right to request their personal data from companies (see Table 2).

Table 2. Summary of Data Protection Regulation in Europe (Teatini and Matinmikko-Blue, 2020)

\begin{tabular}{|l|l|}
\hline \multicolumn{2}{|c|}{ Data Protection Regulation in Europe } \\
\hline & $\begin{array}{l}\text { New privacy regulation approved by the Finnish government in } 2018 \text { goes a step } \\
\text { further than the GDPR protecting. The new legislation also increases the power of } \\
\text { regulators to administer steep fines on individuals and institutions that breach the } \\
\text { law. Based on the new law, children's date and age of consent states that public and } \\
\text { private institutions, including individuals, will no longer be able to retrieve data of } \\
\text { minors younger than 13 years old }\end{array}$ \\
\hline $\begin{array}{l}\text { Germany has historically had some of the most comprehensive data protection laws } \\
\text { in Europe. The German Federal Data Protection Act (Bundesdatenschutzgesetz) was }\end{array}$ \\
adopted in 1970. In the following decade, Constitutional Court drew a distinction \\
between the right to information self-determination from the right to respect for \\
personality. In 2001, the parliament amended the Federal Data Protection Act by \\
creating a provision, which incorporated the recommendations of EU Directive \\
$94 / 46 / E C$. Since 2009, Germany has had some of the strictest data protection laws in \\
Europe. However, as the GDPR supersedes national law, German regulators are \\
required to apply GDPR standards when necessary
\end{tabular}




\begin{tabular}{|c|c|}
\hline & $\begin{array}{l}\text { French Data Protection Bill was introduced by the Ministry of Justice in } \\
\text { ecember of } 2017 \text {. The new proposed legislation revises the previous } 1978 \text { French } \\
\text { ate Protection Act. The new bill attempts to balance the increased need for access } \\
\text { personal data with the necessity to protect the privacy of some critical data, such } \\
\text { medical records, criminal records, data of underage citizens, genetic data, etc. In } \\
17 \text {, France passed a data protection law which called for the lowering of the age of } \\
\text { nsent from } 16 \text { to } 15 \text { years old. In addition, in } 2018 \text {, France adopted a law that } \\
\text { poses hefty fines, up to } 125000 \text { euros, on operators that fail to provide adequate } \\
\text { ta protection to users }\end{array}$ \\
\hline 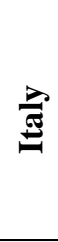 & $\begin{array}{l}\text { ather than passing new a legislation, a decree was signed in } 20 \\
\text { perators to comply with the GDPR by introducing new cc } \\
\text { iidelines. The decree maintained GARANTE as the national d } \\
\text { charge of guaranteeing compliance with the new EU legisla } \\
\text { ipulates that the age of consent was reduced to } 14 \text { years old an } \\
\text { quired to design simple, clear, concise, and objective consent }\end{array}$ \\
\hline & $\begin{array}{l}\text { The privacy and data protection law was enacted in Dece } \\
\text { Protection of Personal Data and the Guarantee of Digital Rights } \\
\text { issues: political parties and personal data processing, digital righ } \\
\text { the law, data subject rights, and data protection officers. The } \\
\text { goes a step beyond the EU law by offering increased personal }\end{array}$ \\
\hline & $\begin{array}{l}\text { In June of 2018, Portugal passed the Execution Law of the General Data Protection } \\
\text { Regulation. A regulation approved by the Portuguese Data Protection National } \\
\text { Commission lists the types of activities to be covered by the Data Protection Impact } \\
\text { Assessment (DPIA). The purpose is to mitigate the threats posed by unnecessary } \\
\text { exposing of personal data during the implementation of projects, systems, protocols, } \\
\text { strategies, and policies. The types of data included are health data electronic devices, } \\
\text { large scale profiling data, locators and trackers of individual subjects by } \\
\text { organizations, biometric data for identification and genetic data }\end{array}$ \\
\hline & $\begin{array}{l}\text { In case of the Netherlands, the GDPR re } \\
\text { Dutch Data Protection Authority (DPA) } \\
\text { obligations to GDPR ahead of its EU c } \\
\text { failure to comply may result in the in } \\
\text { depending on the type and severity }\end{array}$ \\
\hline & $\begin{array}{l}\text { Polish Data Protection Act (PDPA) was passed in order to facilitate the } \\
\text { plementation of the EU's GDPR. However, the PDPA lacks enforcement } \\
\text { chanisms as authorities are not allowed to institute fines when an infraction has } \\
\text { an detected. In addition, Poland is in the process of adjusting other laws, such as } \\
\text { ecommunications, commerce, and copyright in order to comply with GDPR. This } \\
\text { rk falls under the jurisdiction of the Ministry of Digitization. One of the concerns } \\
\text { ught forth is the low fines instituted for public agencies, which is capped at } 25\end{array}$ \\
\hline
\end{tabular}




\begin{tabular}{|l|l|}
\hline In 2000, the Danish government enacted the Danish Act on Process of Personal \\
Information in which it stated that personal data should be collected only for \\
specific, legal and explicit reasons. It also stated that it should be accurate and not be \\
excessive. The Danish Data Protection Act was passed in 2018 and it adopts and \\
amends the GDPR by including in the regulation sections that were specifically \\
designed to be interpreted by nation states
\end{tabular}

Source: Developed by the authors.

Despite the huge potential for large fines imposed by regulators, there is a high level of ignorance of the GDPR provisions in the business environment. A recent survey conducted in the UK shows that only $40 \%$ of firms are aware of the new law and their own responsibilities to ensure compliance with GDPR (Sharma, 2020a). Guidelines on data privacy and GDPR help organizations strictly adhere to legislation within the EU, the US and other countries (Kloza et al., 2017).

The GDPR impose numerous restrictions and sets rules for daily data processing, external interaction with consumers and foreign countries. Elements of the GDPR are subjective (Sharma, 2020b) and may lead to the inability of some foreign countries to interact with EU countries because of data processing rules (Christou, 2017). The processing of data and information under the GDPR requires a legal basis in accordance with regulation. The GDPR is centralized in the field of data collection, limiting the volume of collection, authorizing certain types of international data transfer, ensuring compliance with EU law (Freitas, Moreira and Andrade, 2017). On the one hand, the GDPR facilitate the exchange of data during intragroup processing, which requires organizations to take a more careful approach to compliance. On the other hand, the GDPR oblige for cooperation between countries, while limiting the possibility of applying foreign laws and court rulings if they do not comply with the EU's regulatory framework (Sharma, 2020b).

Researchers criticize the European Court for shortcomings in identifying, at an early stage, various elements (Neves, 2020), that need to be balanced in assessing the proportionality of data processing interference with human rights for legitimate purposes pursued by data controllers. The European Court has not examined in detail the legitimate interests of data controllers in data processing or the rights of data subjects who violate such processing (Neves, 2020). Thus, the weighing and discussion of these elements in the European Court was presented as inadequate and even as "impossible" (Fontanelli, 2016), there was criticism of the proportionality in the constitutional court (Niglia, 2016; Tsakyrakis, 2010).

\section{Conclusion}

The current personal data protection mechanism in the EU is characterized by a fundamentally new approach to data protection: human-centered and innovative in terms of personal data management. Protection authorities establish cooperation on the basis of a "single-window" mechanism and use mutual assistance, in particular, 
in cross-border cooperation on data protection. Given the need to implement the mechanism in all EU countries, the level of flexibility and adaptability can be described as high. At the same time, the fragmentary nature of the implementation of legal provisions proves the need to increase the level of flexibility. The priority of rights differs within the EU, which leads to differences regarding the implementation of the personal data protection mechanism.

Another problem of the new mechanism concerns the problems of business (including multinational companies) in the implementation of innovations, new technological developments, solving problems in the field of cybersecurity. The current protection mechanism corresponds to the concepts of sustainable development and digital transformation, where a person is a partner of the state and has the right to dispose of their own data as a participant in the digital market and the owner of the resource in the form of personal data. The data became the new currency of exchange and the factor of production.

\section{References:}

African Commission on Human and Peoples' Rights. 2013. Model Law on Access to Information for Africa 2013. Available at: https://www.achpr.org/legalinstruments/detail?id=32.

African Commission on Human and Peoples Rights. 2016. 362 Resolution on the Right to Freedom of Information and Expression on the Internet in Africa - ACHPR/Res. 362(LIX)2016. Available at: https://www.achpr.org/sessions/resolutions?id=374.

African Commission on Human and Peoples' Rights. 2019. Declaration of Principles on Freedom of Expression in Africa. Available at: https://www.achpr.org/public/Document/file/English/draft_declaration_of_principles on freedom of expression in africa eng.pdf.

Bentzen, H.B., Høstmælingen, N. 2019. Balancing protection and free movement of personal data: the new European Union General Data Protection Regulation. Annals of Internal Medicine, 170(5), 335-337.

Christou, G. 2017. European Union Privacy and data protection policy. In: Zahariadis, N., \& Buonanno, L. (Eds.), The Routledge Handbook of European Public Policy. Routledge, Abingdon, UK, 179-187.

European Commission. 2016. Regulation (EU) 2016/679 of the European Parliament and of the Council of 27 April 2016 on the protection of natural persons with regard to the processing of personal data and on the free movement of such data, and repealing Directive 95/46/EC. Available at: https://eur-lex.europa.eu/legalcontent/EN/TXT/PDF/?uri=CELEX:32016R0679.

European Commission. 2020. Communication from the commission to the European Parliament and the Council. Data protection as a pillar of citizens' empowerment and the EU's approach to the digital transition - two years of application of the General Data Protection Regulation. Available at: https://ec.europa.eu/info/sites/info/files/1_en_act_part1_v6_1.pdf.

Fontanelli, F. 2016. The Mythology of proportionality in judgments of the Court of Justice of the European Union on internet and fundamental rights. Oxford Journal of Legal Studies, 36, 630-660. 
Freitas, P.M., Moreira, T.C., Andrade, F. 2017. Data protection and biometric data: European Union legislation. In Jiang, R., Al-maadeed, S., Bouridane, A., Crookes, D. \& Beghdadi, A. (Eds.), Biometric Security and Privacy: Opportunities \& Challenges in The Big Data Era. Springer, Cham, 413-421.

Guinchard, A. 2018. Taking proportionality seriously: The use of contextual integrity for a more informed and transparent analysis in EU data protection law. European Law Journal, 24(6), 434-457.

Ilina, E.L., Miloradov, K.A., Kovaltchuk, A.P. 2019. 'Green Hotel': Concepts and implementation. Journal of Environmental Management and Tourism, 10(2), 300-306.

Kloza, D., van Dijk, N., Gellert, R., Böröcz, I., Tanas, A., Mantovani, E., Quinn, P. 2017. Data protection impact assessments in the European Union: complementing the new legal framework towards a more robust protection of individuals. Brussels Laboratory for Data Protection \& Privacy Impact Assessments Policy Brief, Brussels.

Laurer, M., Seidl, T. 2020. Regulating the European data-driven economy: A case study on the general data protection regulation. Policy \& Internet. https://doi.org/10.1002/poi3.246.

Lewinski, P., Trzaskowski, J., Luzak, J. 2016. Face and emotion recognition on commercial property under EU Data Protection Law. Psychology \& Marketing, 33(9), 729-746.

Martínez-Martínez, D.F. 2018. Unification of personal data protection in the European Union: Challenges and implications. El profesional de la información, 27(1), 185-194.

Neves, A. 2020. Protection of personal data regulation and public liberties: A polyhedron with unexpected effects. In Tzanou, M. (Ed.), Personal Data Protection and Legal Developments in the European Union. IGI Global, Hershey, PA, 1-18.

Niglia, L. 2016. Eclipse of the Constitution (Europe Nouveau Siècle). European Law Journal, 22(2), 132-156.

Sharma, S. 2020a. GDPR's Scope of Application. In Sharma, S. (Ed.), Data Privacy and GDPR Handbook. Wiley, Hoboken, NJ, 45-57.

Sharma, S. 2020b. Material Requisites for Processing under GDPR. In Sharma, S. (Ed.), Data Privacy and GDPR Handbook. Wiley, Hoboken, NJ, 125-192.

Teatini, S., Matinmikko-Blue, M. 2020. Privacy in the 5G world: The GDPR in a datafied society. In Tafazolli, R., Chatzimisios, P. \& Wang, C.-L. (Eds.), Wiley 5G Ref: The Essential 5G reference Online. Wiley. https://doi.org/10.1002/9781119471509.w5GRef173.

Tsakyrakis, S. 2010. Proportionality: An assault on human rights?: A rejoinder to Madhav Khosla. International Journal of Constitutional Law, 8(2), 307-310.

Ungureanu, C.T. 2018. Legal remedies for personal data protection in European Union. Logos, Universality, Mentality, Education, Novelty. Section: Law, 6(2), 26-47.

Van Loenen, B., Kulk, S., Ploeger, H. 2016. Data protection legislation: A very hungry caterpillar: The case of mapping data in the European Union. Government Information Quarterly, 33(2), 338-345. 